\title{
Deformability and Volume of Neonatal and Adult Leukocytes
}

\author{
PETER RUEF, THOMAS BÖHLER, AND OTWIN LINDERKAMP \\ Division of Neonatology, Department of Pediatrics, University of Heidelberg, Heidelberg, \\ Federal Republic of Germany
}

\begin{abstract}
Volume and deformability of blood cells are important determinants of the microcirculation. Leukocytes are larger and considerably less deformable than erythrocytes. In our study, volume and deformability of polymorphonuclear neutrophils (PMN), lymphocytes, and monocytes in adults and full-term neonates were studied by means of a micropipette system. Neonatal immature granulocytes were also investigated. Membrane cytoplasm tongues were aspirated into $2.5-\mu \mathrm{m}$ (diameter) micropipettes over a period of $1 \mathrm{~min}$. Adult and neonatal PMN were totally aspirated into 5- $\mu \mathrm{m}$ micropipettes. Tongue growth and final tongue length of PMN were about twice those of monocytes and lymphocytes. At a pressure of -2 cm $\mathrm{H}_{2} \mathrm{O}$, tongue growth of lymphocytes and monocytes was similar. At a pressure of $-4 \mathrm{~cm} \mathrm{H}_{2} \mathrm{O}$, however, tongue growth of monocytes was faster and the final tongue was longer than those of lymphocytes $(p<0.05)$. Cellular volume and deformation behavior of the different leukocyte subpopulations (PMN, monocytes, and lymphocytes) were similar in neonates and adults. Compared to mature neonatal PMN, immature neonatal neutrophilic granulocytes were significantly less deformable (final tongue length of $5.4 \pm 1.52$ versus $9.3 \pm 1.48 \mu \mathrm{m}$ at $-2 \mathrm{~cm} \mathrm{H}_{2} \mathrm{O}$ ) and larger $(421 \pm 68$ versus $360 \pm 38 \mathrm{fL})$. The entry time of PMN into 5- $\mu \mathrm{m}$ micropipettes was similar in neonates and adults at aspiration pressures of $-2,-3$, and $-4 \mathrm{~cm} \mathrm{H}_{2} \mathrm{O}$. We conclude that the deformability of neonatal and adult leukocytes is not different despite functional differences and that immature granulocytes may contribute to impaired microcirculation in neonates with severe septicemia or hypoxemia. (Pediatr Res 29: 128-132, 1991)
\end{abstract}

Abbreviations

PMN, polymorphonuclear leukocytes

Leukocytes play an important role in the microcirculation (1). Compared with erythrocytes, leukocytes have two to five times larger volumes and 700 to 1000 times higher flow resistance through $5-\mu \mathrm{m}$ filter pores (2). Viscosity of adult leukocytes is more than 1000 times higher than the intracellular viscosity of erythrocytes $(3,4)$. In vivo studies have shown that fast-moving erythrocytes are blocked behind more slowly moving leukocytes in capillaries with diameters less than $15 \mu \mathrm{m}$. These "cell-trains" cause an increased resistance of capillary blood flow (1). Plugging may occur in capillaries with diameters less than those of leukocytes (5). This becomes important at low peripheral pressure,

Received July 24, 1990; October 9, 1990.

Correspondence and reprint requests: Dr. Otwin Linderkamp, Universitätskinderklinik Heidelberg, Im Neuenheimer Feld 150, D-6900 Heidelberg, FRG.

Supported by a research grant (Li 291/4-3) from the Deutsche Forschungsgemeinschaft. e.g. in shock ("no-reflow" phenomenon) (6) or in ischemia of various organs (7). Small vessel obstruction by leukocytes appears to play a role in the pathogenesis of septic shock (8).

The blood of healthy neonates contains more leukocytes (6000-26 000/ $\mu \mathrm{L})$ and more immature (band and juvenile) granulocytes (up to $20 \%$ of the granulocytes) than adult blood (9). In severe neonatal septicemia, up to $100 \%$ of the granulocytes may be immature.

Neonatal leukocytes show several functional differences compared with adult leukocytes (10-13). Functional defects in neonatal polymorphonuclear granulocytes include impaired adherence, diminished phagocytosis, lower bactericidal activity, decreased chemotaxis, decreased receptor capping, and diminished intracellular killing. Random mobility (i.e. nondirected movement without chemotactic stimuli) is not different in adult and neonatal neutrophilic granulocytes $(14,15)$. Neonatal granulocytes require higher aspiration pressures for total aspiration into micropipettes with internal diameters of $3-5 \mu \mathrm{m}(14,16)$, and neonatal leukocytes impair the filterability of whole blood suspensions more than adult leukocytes (17). Miller (14) proposes that functional abnormalities of neonatal PMN are related to impaired deformability.

Whole cell aspiration into micropipettes and filtration of leukocytes are strongly influenced by the cell size. Micropipette techniques have recently been developed to study the timedependent leukocyte deformation pattern independent of the cell size. A membrane-cytoplasm tongue is aspirated into narrow pipettes with a diameter of approximately $2.5 \mu \mathrm{m}$ and the tongue growth is recorded $(3,18,19)$. This method has only been used for adult PMN and lymphocytes.

Our study was designed to investigate rheologic properties of various leukocyte subpopulations (i.e. PMN, immature neutrophilic granulocytes, lymphocytes, and monocytes) from term neonates and adults. We studied the rate of deformation of cytoplasm tongues aspirated into $2.5-\mu \mathrm{m}$ pipettes and determined the volumes of the leukocytes. Because Miller (14) reported decreased whole cell deformability of neonatal PMN, we also studied the time required for complete entry of mature neonatal and adult PMN into 5- $\mu \mathrm{m}$ pipettes.

\section{MATERIALS AND METHODS}

Blood samples and leukocyte preparation. Placental blood samples from five infants were studied with the approval of the Department of Pediatrics Human Subjects Committee. They were healthy, full-term infants with gestational ages of 38 to 41 wk and birth weights of 3520 to $3870 \mathrm{~g}$. Infants with malformations, erythroblastosis, diabetic mothers, hemorrhage, or cesarean section were excluded, as were twins and infants with proven infection or high risk of infection. The 1-min Apgar score was 9 and the 2- and 5-min Apgar scores were 10 in all cases. All infants had birth weights appropriate for gestational age (10th90th percentile according to unpublished Munich charts) and umbilical artery $\mathrm{pH}$ above 7.25 . Blood $(10 \mathrm{~mL})$ was collected 
from the placenta into EDTA immediately after cord clamping before delivery of the placenta. A sample volume of $10 \mathrm{~mL}$ was necessary and ruled out serial studies in the neonates after birth. Adult blood samples $(10 \mathrm{~mL})$ were collected from five healthy male laboratory personnel by venipuncture into EDTA.

The blood was centrifuged at $350 \times g$ and $4^{\circ} \mathrm{C}$ for $25 \mathrm{~min}$. Plasma and buffy coat were carefully removed and stored separately in sterile plastic tubes at $4^{\circ} \mathrm{C}$. A solution $(\mathrm{pH} \mathrm{7.4,295}$ mosmol/kg) of PBS $\left(\mathrm{Na}_{2} \mathrm{HPO}_{4} 3.53 \mathrm{~g} / \mathrm{L} ; \mathrm{KH}_{2} \mathrm{PO}_{4} 0.702 \mathrm{~g} / \mathrm{L}\right.$; $\mathrm{NaCl} 7.0725 \mathrm{~g} / \mathrm{L}$ ) and $5 \%$ autologous plasma was prepared and stored at $4^{\circ} \mathrm{C}$. Ten $\mu \mathrm{L}$ of the buffy coat were diluted into the PBS-plasma solution.

Leukocytes were taken directly from the buffy coat. The leukocyte subpopulations were identified during the microscopic deformation studies. This method avoids the influence of a separation medium on leukocyte properties (e.g. Ficoll) (20). Granulocytes were identified by their size and granules. PMN and immature granulocytes were distinguished by the shape of their nucleus. An immature granulocyte was defined as a neutrophil in which the width of the narrowest segment of the nucleus was not less than one third of the broadest segment. Band and juvenile granulocytes were not distinguished and were called immature granulocytes. Eosinophilic and basophilic granulocytes were recognized by their larger and darker granules compared with neutrophilic granulocytes and were not studied. Lymphocytes were identified as the smallest leukocytes with a round and large nucleus surrounded by a thin plasma layer. Monocytes were defined as the cells with the largest volume and with a kidney-shaped nucleus that was often seen close to the membrane. Monocytes contain a larger amount of cytoplasm in relation to the nucleus than lymphocytes. Both cell types contain few or no granules.

Micropipette system. Micropipettes of the desired diameter were made from borosilicate glass capillaries (Glaswerk, Wertheim, FRG) using a pipette puller (Effenberger, Pfaffing/Attel, FRG). Flat pipette tips were produced under microscopic observation using a modification (21) of the technique described by Nash and Meiselman (19). The micropipettes were filled with filtered $A B$ plasma (of an adult person) and stored in tubes filled with sterile and filtered $\mathrm{AB}$ plasma-PBS solution (10\% $\mathrm{AB}$ plasma, $90 \% \mathrm{PBS}$ ) at $4^{\circ} \mathrm{C}$. This procedure allows repeated usage of the same micropipette. For this study, only one $5-\mu \mathrm{m}$ micropipette and two $2.5-\mu \mathrm{m}$ micropipettes were used.

For the experiments, the micropipette was mounted in a pneumatic micromanipulator (de Fonbrune, Paris, France) and connected to a water-filled reservoir. Zero and aspiration pressures applied to the micropipette tip were adjusted by moving the reservoir vertically using a precision micrometer, thus allowing $0.01 \mathrm{~mm} \mathrm{H}_{2} \mathrm{O}$ pressure resolution. The pressure system was calibrated with a piezo-resistive pressure transducer (sensor: model SN R 16, Druckmesstechnik Keller AG, Winterthur, Switzerland).

The separately stored autologous plasma was filtered with a Sterivex-Gs $0.22-\mu \mathrm{m}$ filter unit (Millipore Corp., Bedford, MA) and filled into a $U$-shaped microchamber $(6 \mathrm{~mm} \times 10 \mathrm{~mm} \times 1$ $\mathrm{mm}$ ) formed by a standard microscope slide and two coverslips. The micropipette was positioned into the chamber and a small negative pressure was applied to fill the tip of the pipette with autologous plasma. This procedure prevents cell-to-glass contact on the surface of the pipette and the chamber. After $10 \mathrm{~min}$ the pipette was removed and the plasma was carefully blown out of the chamber by compressed nitrogen. The chamber was filled with the diluted cell suspension and the pipette was repositioned into the chamber.

A microscope-video system was used for the leukocyte measurements. Its basic components include: (1) an inverted microscope (model Diavert, Leitz, Wetzlar, FRG) with $50 \times$, numerical aperture $=1.0$ water immersion objective and $2 \times$ optical lens converter; (2) a $1 / 2$-inch CCD-Video camera (Panasonic WV CD 110 E, Matsushita Electric, Tokyo, Japan); (3) a video tape recorder (Panasonic AG 6200 EG, Matsushita Electric); (4) a contour synthesizer (model IV-530, FOR-A Ltd., Tokyo, Japan); (5) a video timer (model VTG-33, FOR-A Ltd.); (6) a 14-inch video monitor (Panasonic TC 431 DRP, Matsushita Electric); (7) a high-precision microscope micrometer (Kalibriernormal Nr.060-643.008 (1), Leitz); and (8) a video analyzing system (MOP-Videoplan, Kontron, München, FRG). The contour synthesizer converts differences in density within the image into differences in contour so that the visibility of minute details is enhanced. The optical magnification of the microscope was $788 \times$. The additional electronic magnification of the video system resulted in a final magnification of $4000 \times$. The video picture was calibrated with a micrometer (calibration bars of $20 \pm 0.2$ $\mu \mathrm{m}$ ) in an overlay of the video analyzing system.

Leukocyte deformation. Pipettes with internal diameters of 2.5 $\mu \mathrm{m}$ were used to aspirate membrane-cytoplasm tongues of leukocytes (Fig. 1). Different aspiration pressures in the range of 1 to $4 \mathrm{~cm} \mathrm{H}_{2} \mathrm{O}$ were applied. The tip of the pipette was placed adjacent to the leukocyte to be tested, and the deformation process was video recorded. Except for the monocytes, measurements in each sample were made for five to 10 cells of each cell type. Monocytes were not found in two of the five neonatal samples. In the other three neonatal samples and in the five adult samples, two to five monocytes were studied. The cell tongues were ejected out of the pipette after the deformation studies. Most cells recovered to their initial shape and remained passive. This process needed several minutes and was not further analyzed. The length of the aspirated tongue was measured from the video recording after $5,10,20,40$, and $60 \mathrm{~s}$. The recordings were displayed on the screen of the computerized video analyzing system and the tongue lengths were measured by means of a cursor and a magnetic tablet. Resting leukocytes have an overall spherical shape so that the volumes can easily be calculated by the video analyzer from the encircled cross-sectional area. A pipette with an internal diameter of $5 \mu \mathrm{m}$ was used to measure the time required for complete entry of adult and neonatal segmented granulocytes (Fig. 2). Fixed pressures ( $-2,-3$, and $-4 \mathrm{~cm} \mathrm{H}_{2} \mathrm{O}$ ) were applied and the entry process was video recorded. The time between the first contact of the cell with the pipette tip and the complete entry of the cell into the pipette was measured with a time resolution of $1 / 25 \mathrm{~s}$ (i.e. the video field rate). For each sample, five to 10 cells were studied at each of the three different aspiration pressures.

Leukocyte studies using micropipettes require strict prevention of cell activation. Leukocytes are readily activated by contact with glass surfaces. We observed that the use of plasma-free PBS as suspending medium results in marked leukocyte activation. Compared with the use of pure PBS, there was less activation

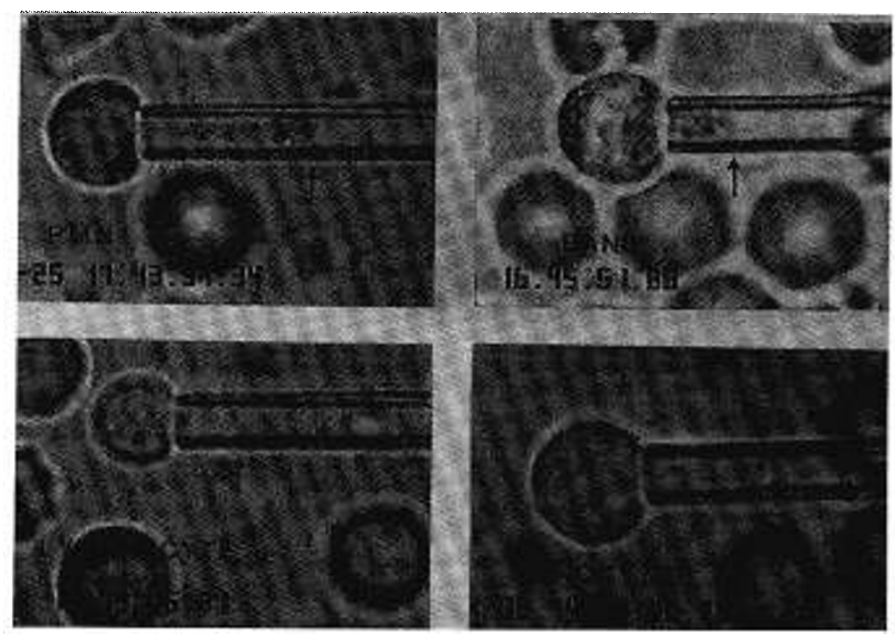

Fig. 1. Leukocytes during tongue formation in $2.5-\mu \mathrm{m}$ diameter micropipettes. Arrows indicate the end of the cell tongues. 


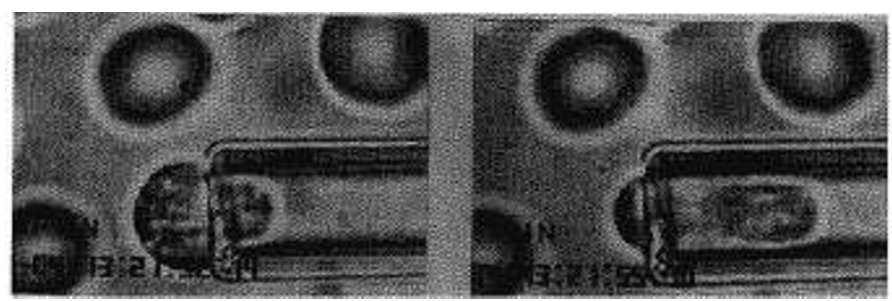

Fig. 2. Entry of a segmented neutrophilic granulocyte into a $5-\mu \mathrm{m}$ diameter micropipette.

when the surfaces of the chamber and the pipette were covered with pure autologous plasma and the cells were suspended in $5 \%$ autologous plasma and 95\% PBS. A protein layer on the glass surfaces probably prevents direct cell-to-glass contact. Moreover, the use of EDTA as anticoagulant results in less leukocyte activation than heparin (22). Nevertheless, our technique did not completely prevent leukocyte activation. Activated cells are extremely rigid, form only small or no tongues at all, and increase their volume $(20,23)$. Moreover, activation of a previously passive cell may result in retraction of the tongue (18). We included in the evaluation only cells that showed a homogeneous spherical shape and that began to deform immediately with the application of a negative pressure. Leukocytes with pseudopods or active retraction of the tongue were excluded. All measurements were carried out at room temperature $\left(22 \pm 1^{\circ} \mathrm{C}\right)$ and were completed within $5 \mathrm{~h}$ of blood sampling.

Statistical analyses. Statistical analyses were performed to test for differences of volume and deformation behavior between neonatal and adult leukocyte subpopulations. Means and SD were calculated for the entire cell population of each leukocyte type separately for neonates and adults. One-way analysis of variance was used to test for differences among the leukocyte subpopulations separately in neonates and adults. If one-way analysis of variance led to rejection of the null hypothesis, Tukey's honestly-significant-difference method and the Newman-Keuls test were used to analyze which groups showed significant differences (24). Both tests gave the same significance levels of differences among various leukocyte subpopulations. One-way analysis of variance was also used to compare corresponding leukocyte subpopulations in neonates and adults.

\section{RESULTS}

Figure 3 shows the time-dependent tongue growth of different leukocyte subpopulations in $2.5-\mu \mathrm{m}$ micropipettes. Adult and neonatal PMN showed steady tongue formation, and the process of tongue elongation was not finished at the end of the observation period of $60 \mathrm{~s}$. Immature granulocytes showed markedly diminished tongue growth compared with PMN (Fig. 3, Table 1). Because of the small numbers of immature granulocytes in the peripheral blood of healthy adults, these cells could only be studied for neonates.

Lymphocytes and monocytes showed a steep increase in tongue growth during the first $10 \mathrm{~s}$. Further tongue growth was very slow but did not end during the observation time (Fig. 3).

PMN, lymphocytes, and monocytes of adults and neonates were studied at two different aspiration pressures (Fig. 3). The absolute tongue lengths increased more rapidly at higher aspiration pressures. However, the shapes of the curves of each leukocyte subpopulation were not affected by the applied pressure. At an aspiration pressure of $-2 \mathrm{~cm} \mathrm{H}_{2} \mathrm{O}, \mathrm{PMN}$ showed the fastest tongue growth (Fig. 3, Table 1).

Significant differences between adults and neonates were only observed for lymphocytes after $5 \mathrm{~s}$ of deformation (Table 1). At a pressure of $-2 \mathrm{~cm} \mathrm{H}_{2} \mathrm{O}$, tongue growth of lymphocytes and monocytes was similar. At a pressure of $-4 \mathrm{~cm} \mathrm{H}_{2} \mathrm{O}$, however, tongue growth of monocytes was faster and the final tongue was longer than that of lymphocytes in both neonates $(p<0.05)$ and adults $(p<0.01)$.

The entry time of PMN into 5- $\mu \mathrm{m}$ micropipettes did not show a significant difference between neonates and adults at any of the three aspiration pressures (Table 1).

Neonatal immature neutrophilic granulocytes were considerably larger than neonatal PMN $(p<0.01)$. The volumes of the leukocyte subpopulations did not differ between neonates and adults (Table 2).

\section{DISCUSSION}

Passive deformation of leukocytes depends principally on the same factors as deformation of red blood cells (i.e. surface area excess, shape, and viscoelastic properties of the membrane and the cell content). Granulocytes have an excess of the membrane surface area of approximately $100 \%$ beyond that required to cover a sphere of the same volume $(3,4)$. The excess membrane is used to form folds and enables leukocytes to enter capillaries with diameters smaller than $3 \mu \mathrm{m}$. The time needed for the deformation process during the entry of a white blood cell into narrow capillaries is determined by its volume, its viscoelastic properties, and the applied pressure.

Leukocyte subpopulations differed considerably in their deformation behavior (Fig. 3). PMN deformed better than monocytes and lymphocytes. The different deformation behavior of PMN and lymphocytes in adults has been shown by other authors using a similar micropipette technique (19). Lichtman and Weed (25) reported that bone marrow PMN and monocytes require a low negative pressure for aspiration of a hemispherical membrane-cytoplasm bulge into $3.5-\mu \mathrm{m}$ pipettes. We observed that monocytes showed slower membrane-cytoplasm deformation than PMN (Fig. 3).

Neonatal and adult PMN showed similar whole cellular (Table 1) and membrane-cytoplasm deformability (Fig. 3). This contradicts the results of Miller $(16,26)$, who found decreased deformability of neonatal PMN using a cell elastimeter for whole cell aspiration into micropipettes with diameters of 3 to $5 \mu \mathrm{m}$. The discrepancy may be due to several differences in the experimental conditions: (1) Miller used heparinized blood samples. Heparin is a strong activator of PMN. Because activated PMN are extremely rigid, the results may have been influenced by PMN activation. (2) It is unclear whether Miller separated mature and immature granulocytes. Our study showed markedly diminished deformability of immature granulocytes when compared with mature PMN (Fig. 3). (3) The pressure required for aspiration of PMN granulocytes into micropipettes is strongly time-dependent (18). In our study, a pressure of $-2 \mathrm{~cm} \mathrm{H}_{2} \mathrm{O}$ was sufficient for complete aspiration of neonatal and adult PMN into micropipettes (Table 1). Miller reports aspiration pressures of $-19 \mathrm{~cm}$ $\mathrm{H}_{2} \mathrm{O}$ for adult and $-75 \mathrm{~cm} \mathrm{H}_{2} \mathrm{O}$ for neonatal PMN (16). Our finding of decreased deformability of immature granulocytes agrees with the observation of Lichtman and Weed (27), who found markedly diminished deformability of adult marrow myelocytes and myeloblasts in a cell elastimeter. The reduced deformability of immature granulocytes was probably due to a more viscous cytoplasm and not to a larger nucleus, inasmuch as tongue growth was already decreased at the beginning of tongue aspiration.

Monocytes and lymphocytes showed similar deformation behavior (Fig. 3). An initial steep tongue growth was followed by slow further deformation. At a pressure of $-4 \mathrm{~cm} \mathrm{H}_{2} \mathrm{O}$, the final deformation of monocytes was, however, stronger than that of lymphocytes. This difference may be due to a larger cytoplasmto-nucleus ratio of monocytes compared with lymphocytes.

Neonatal lymphocytes showed shorter membrane-cytoplasm tongues than adult lymphocytes after $5 \mathrm{~s}$ (Table 1). This may be explained by different lymphocyte subpopulations in neonates and adults. In comparison to adult blood, neonatal blood contains fewer B cells (14 versus $27 \%$ ) and fewer T cells (55 versus 

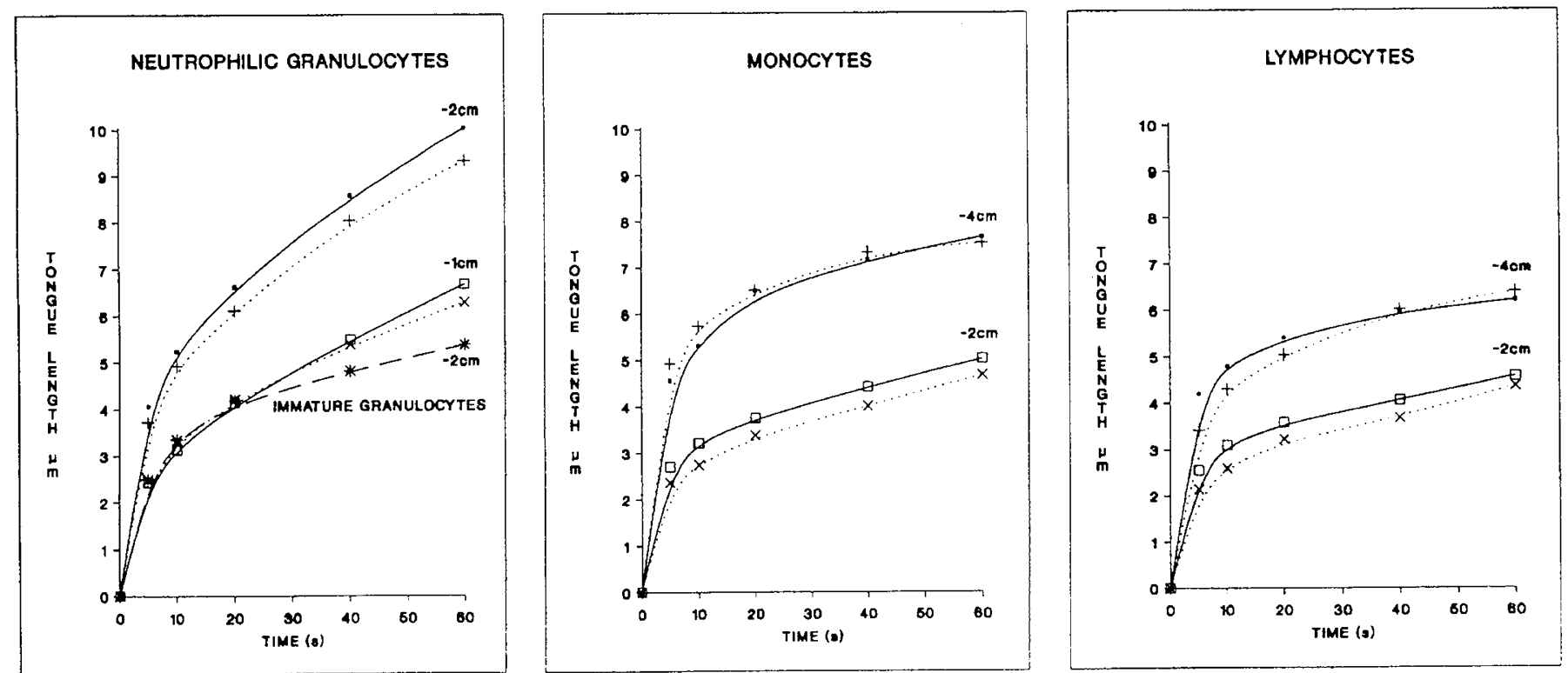

Fig. 3. Time-dependent membrane cytoplasm tongue formation of neonatal (dotted lines and open symbols) and adult (solid lines and closed symbols) segmented neutrophilic granulocytes, monocytes, and lymphocytes in 2.5- $\mu \mathrm{m}$ micropipettes. Immature neutrophilic granulocytes (broken line) were studied only in neonates. The negative numbers are the applied aspiration pressures $\left(-1\right.$ to $\left.-4 \mathrm{~cm} \mathrm{H}_{2} \mathrm{O}\right)$.

Table 1. Tongue length and time for whole cell aspiration of adult $(A)$ and neonatal $(N)$ leukocytes*

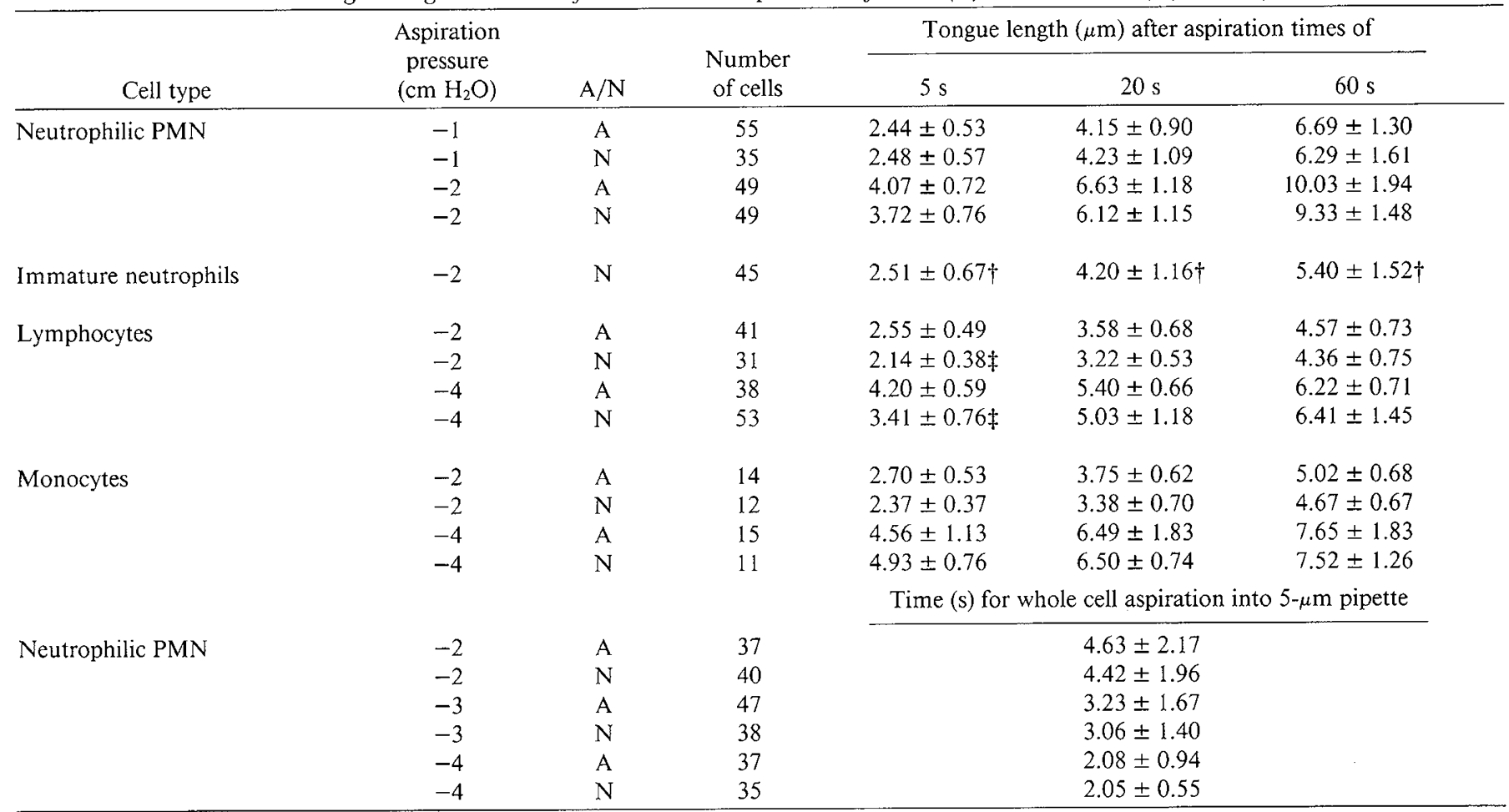

* Data represent mean $\pm 1 \mathrm{SD}$ of the entire leukocyte subpopulation in each group.

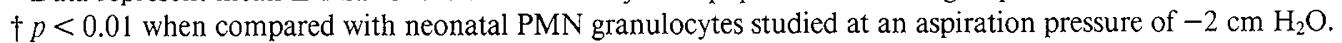

$\ddagger p<0.01$ when compared with adult lymphocytes studied at same aspiration pressure.

$67 \%$ ) but more null cells (31 versus 6\%) (28). Chien et al. (29) determined a higher coefficient of viscosity for $T$ lymphocytes compared with $\mathrm{B}$ lymphocytes in adults. Thus, the relatively higher $\mathrm{T}$-to-B cell ratio in neonates may have caused the small difference in tongue growth between adult and neonatal lymphocytes. Deformability of isolated null lymphocytes has apparently not been studied.

Our volume measurements did not reveal significant differences between neonatal and adult leukocytes. Yasui et al. (15) have also determined similar volumes of neonatal and adult
PMN by means of cell cytometry. Volume measurements of adult leukocyte subpopulations obtained in our study agree well with previous reports $(24,30)$.

Leukocyte properties may be altered by stress (31). We tried to minimize possible effects of birth stress by selection of healthy full-term neonates with normal Apgar scores and arterial $\mathrm{pH}$ at birth.

We conclude that neither the volume nor the deformability of PMN, lymphocytes, and monocytes differs between neonates and adults. Because time-dependent cell deformation is strongly 
Table 2. Volumes of adult and neonatal leukocyte subpopulations*

\begin{tabular}{lcccc}
\hline \multicolumn{1}{c}{ Cell type } & $\begin{array}{c}\text { Number } \\
\text { of cells }\end{array}$ & $\begin{array}{c}\text { Volume (fL) } \\
\text { of adult } \\
\text { leukocytes }\end{array}$ & $\begin{array}{c}\text { Number } \\
\text { of cells }\end{array}$ & $\begin{array}{c}\text { Volume } \\
\text { (fL) of } \\
\text { neonatal } \\
\text { leukocytes }\end{array}$ \\
\hline $\begin{array}{l}\text { Neutrophilic PMN } \\
\text { Immature neutrophils }\end{array}$ & 85 & $370 \pm 41$ & 90 & $360 \pm 38$ \\
Lymphocytes & 74 & $233 \pm 29 \ddagger$ & 100 & $235 \pm 35 \ddagger$ \\
Monocytes & 27 & $532 \pm 60 \ddagger$ & 21 & $519 \pm 66 \ddagger$ \\
\hline
\end{tabular}

$*$ Data represent mean \pm 1 SD of the entire leukocyte subpopulation in each group.

$\dagger p<0.01$ when compared with neonatal segmented granulocytes.

$\ddagger p<0.01$ when compared with the PMN granulocytes of the same group (i.e. neonates or adults, respectively).

influenced by viscous properties $(4,29)$, our results suggest that the membrane-cytoplasm viscosity of neonatal and adult leukocytes is not different. In this context, it is interesting to note that membrane viscosity and cytoplasm viscosity of neonatal and adult red blood cells are also similar (32). Despite similar leukocyte deformability in neonates and adults, leukocytes may have a greater impact on neonatal circulation because the total leukocyte count and the percentage of immature granulocytes are higher in neonates than in adults. Moreover, the bone marrow may release a large number of immature granulocytes as a result of neonatal hypoxia or septicemia (33). A high percentage of large and rigid immature granulocytes may contribute to compromised microcirculation in hypoxic and septic neonates.

Acknowledgments. The authors gratefully acknowledge the expert technical assistance of Thomas Weiss, who also constructed and refined the micropipette-forge and the pressure transducer system. We thank Vivian M. Vargas, M.S.B.A., for her help in preparing the manuscript and the midwives and physicians of the neonatal intensive care unit for taking the blood samples.

\section{REFERENCES}

1. Gaehtgens P 1987 Pathways and interactions of white cells in the microcirculation. Prog Appl Microcirc 12:51-65

2. Chien S, Schmalzer EA, Lee MML, Impelluso T, Skalak R 1983 Role of white blood cells in filtration of blood cell suspensions. Biorheology 20:11-27

3. Schmid-Schönbein GW, Sung K. Tözeren H, Skalak R, Chien S 1981 Passive mechanical properties of human leukocytes. Biophys J 36:243-256

4. Evans E, Yeung A 1989 Apparent viscosity and cortical tension of blood granulocytes determined by micropipet aspiration. Biophys J 56:151-160

5. Schmid-Schönbein GW 1987 Capillary plugging by granulocytes and the noreflow phenomenon in the microcirculation. Fed Proc 46:2397-2401

6. Barroso-Aranda J, Schmid-Schönbein GW, Zweifach BW, Engler RL 1988 Granulocytes and no-reflow phenomenon in irreversible hemorrhagic shock. Circ Res 63:437-447

7. Ernst E, Hammerschmidt DE, Bagge U, Matrai A, Dormandy JA 1987 Leukocytes and the risk of ischemic diseases. JAMA 257:2318-2324

8. Rojas J, Larsson LE, Hellerqvist CG, Brigham KL, Gray ME, Stahlman MT 1983 Pulmonary hemodynamic and ultrastructural changes associated with group B streptococcal toxemia in adult sheep and newborn lambs. Pediatr Res. 17:1002-1008

9. Oski FA 1982 Normal blood values in the newborn period. In: Oski FA, Naiman JL (eds) Hematologic Problems in the Newborn. WB Saunders, Philadelphia, pp 1-31

10. Miller ME 1978 Phagocytic cells. In: Miller ME (ed) Host Defenses in the Human Neonate. Grune \& Stratton, New York, pp 59-71

11. Hill HR 1987 Biochemical, structural, and functional abnormalities of polymorphonuclear leukocytes in the neonate. Pediatr Res 22:375-382

12. Krause PJ, Malech HL, Kristie J, Kosciol CM, Herson VC, Eisenfeld L, Pastuszak WT, Kraus A, Seligman B 1986 Polymorphonuclear leukocyte heterogeneity in neonates and adults. Blood 68:200-204

13. Strauss RG 1988 Granulopoiesis and neutrophil function in the neonate. In: Stockman III JA, Pochedly C (eds) Developmental and Neonatal Hematology. Raven Press, New York, pp 87-101

14. Miller ME 1975 Developmental maturation of human neutrophil motility and its relationship to membrane deformability. In: Bellanti JA, Dayton DH (eds) The Phagocytic Cell in Host Resistance. Raven Press, New York, pp 295-307

15. Yasui K, Masuda M, Matsuoka T, Yamazaki M, Komiyama A, Akabane T, Hasui M, Kobayashi Y, Murata K 1988 Abnormal membrane fluidity as a cause of impaired functional dynamics of chemoattractant receptors on neonatal polymorphonuclear leukocytes: lack of modulation of the receptors by a membrane fluidizer. Pediatr Res 24:442-446

16. Miller ME 1975 Pathology of chemotaxis and random mobility. Semin Hematol 12:59-82

17. Linderkamp O. Hammer BJ, Miller R 1986 Filterability of erythrocytes and whole blood in preterm and full-term neonates and adults. Pediatr Res 20:1269-1273

18. Evans E, Kukan B 1984 Passive material behavior of granulocytes based on large deformation and recovery after deformation tests. Blood 64:1028-1035

19. Nash GB, Meiselman HJ 1986 Rheological properties of individual polymorphonuclear granulocytes and lymphocytes. Clin Hemorheol 6:87-97

20. Rothe G, Valet G 1988 Phagocytosis, intracellular $\mathrm{pH}$, and cell volume in the multifunctional analysis of granulocytes by flow cytometry. Cytometry 9:316-324

21. Weiss T, Ruef P, Linderkamp O 1990 A simplified method to produce micropipettes with flat tips. Clin Hemorheol (in press)

22. Nash GB, Jones JG, Mikita J, Christopher B, Dormandy JA 1988 Effects of preparative procedures and of cell activation on flow of white cells through micropore filters. Br J Haematol 70:171-176

23. Grinstein S, Furuya W, Cragoe EJ 1986 Volume changes in activated human neutrophils: the role of $\mathrm{Na}^{+} / \mathrm{H}^{+}$exchange. $\mathrm{J}$ Cell Physiol 128:33-40

24. Namboodiri NK, Carter LF, Blalock HM 1975 Applied multivariate analysis and experimental designs. McGraw-Hill, New York, pp 213-238

25. Lichtman MA, Weed RI 1972 Peripheral cytoplasmic characteristics of leukocytes in monocytic leukemia: relationship to clinical manifestations. Blood 40:52-61

26. Miller ME, Myers KA 1975 Cellular deformability of the human peripheral blood polymorphonuclear leukocyte: method of study, normal variation and effects of physical and chemical alterations. J Reticuloendothel Soc 18:337345

27. Lichtman MA, Weed RI 1972 Alteration of the cell periphery during granulocyte maturation: relationship to cell function. Blood 39:301-316

28. Christiansen JS, Osther K, Peitersen B, Bach-Mortensen N 1976 B, T and null lymphocytes in newborn infants and their mothers. Acta Paediatr Scand 65:425-428

29. Chien S, Schmid-Schönbein GW, Sung K-LP, Schmalzer EA, Skalak R 1984 Viscoelastic properties of leukocytes. In: Meiselman HJ, Lichtman MA, LaCelle P (eds) White Cell Mechanics: Basic Science and Clinical Aspects. Alan R. Liss, New York, pp 19-51

30. Zucker M, Cassen B 1969 The separation of normal human leukocytes by density and classification by size. Blood 34:591-600

31. Krause PJ, Herson VC, Boutin-Lebowitz J, Eisenfeld L, Block C, Lobello T, Maderazo EG 1986 Polymorphonuclear leukocyte adherence and chemotaxis in stressed and healthy neonates. Pediatr Res 20:296-300

32. Linderkamp O, Nash GB, Wu PYK, Neiselman HJ 1986 Deformability and intrinsic material properties of neonatal red blood cells. Blood 67:1244-1250

33. Christensen RD, Bradley PP, Rothstein G 1981 The leukocyte left shift in clinical and experimental neonatal sepsis. J Pediatr 98:191-105 